Advances in Process Systems Engineering - Vol. 2

\title{
STOCHASTIC GLOBAL OPTIMIZATION
}

Techniques and Applications in

Chemical Engineering 


\title{
Advances in Process Systems Engineering
}

Series Editor: Gade Pandu Rangaiah

(National University of Singapore)

\author{
Vol. 1: Multi-Objective Optimization: \\ Techniques and Applications in Chemical Engineering \\ ed: Gade Pandu Rangaiah \\ Vol. 2: Stochastic Global Optimization: \\ Techniques and Applications in Chemical Engineering \\ ed: Gade Pandu Rangaiah
}


Advances in Process Systems Engineering - Vol. 2

\section{STOCHASTIC GLOBAL OPTIMIZATION \\ Techniques and Applications in \\ Chemical Engineering}

\section{editor}

\section{Gade Pandu Rangaiah}

National University of Singapore, Singapore 
Published by

World Scientific Publishing Co. Pte. Ltd.

5 Toh Tuck Link, Singapore 596224

USA office: 27 Warren Street, Suite 401-402, Hackensack, NJ 07601

UK office: 57 Shelton Street, Covent Garden, London WC2H 9HE

\section{British Library Cataloguing-in-Publication Data}

A catalogue record for this book is available from the British Library.

\section{Advances in Process Systems Engineering - Vol. 2 \\ STOCHASTIC GLOBAL OPTIMIZATION \\ Techniques and Applications in Chemical Engineering \\ (With CD-ROM)}

Copyright (C) 2010 by World Scientific Publishing Co. Pte. Ltd.

All rights reserved. This book, or parts thereof, may not be reproduced in any form or by any means, electronic or mechanical, including photocopying, recording or any information storage and retrieval system now known or to be invented, without written permission from the Publisher.

For photocopying of material in this volume, please pay a copying fee through the Copyright Clearance Center, Inc., 222 Rosewood Drive, Danvers, MA 01923, USA. In this case permission to photocopy is not required from the publisher.

Desk Editor: Tjan Kwang Wei

ISBN-13 978-981-4299-20-6

ISBN-10 981-4299-20-0

Typeset by Stallion Press

Email: enquiries@stallionpress.com

Printed in Singapore. 


\section{PREFACE}

In Chemical Engineering, optimization plays a key role in the design, scheduling and operation of industrial reactors, separation processes, heat exchangers and complete plants. It is also being used on a larger scale in managing supply chains and production plants across the world. Furthermore, optimization is useful for understanding and modeling physical phenomena and processes. Without the use of optimization techniques, chemical processes would not be as efficient as they are now. Optimization has, in short, proven to be essential for achieving sustainable processes and manufacturing.

In many applications, the key is to find the global optimum and not just a local optimum. This is desirable as the former is obviously better than the latter in terms of the desired objective function. In some applications such as phase equilibrium, only the global optimum is the correct solution. Finding the global optimum is more challenging than finding a local optimum. Methods for finding the global optimum can be divided into two main groups: deterministic and stochastic (or probabilistic) techniques. Stochastic global optimization (SGO) techniques involve probabilistic elements and consequently use random numbers in the search for the global optimum. They include simulated annealing, genetic algorithms, taboo/tabu search and differential evolution. SGO techniques have a number of attractive features including being simple to understand and program, requiring no assumptions on the optimization problem, the wide range of problems they can solve, their ability to provide robust results for highly nonlinear problems even with many decision variables, and faster convergence towards global optimal solution. 
Significant progress has been made in SGO techniques and their applications in the last two decades. However, there is no book devoted to SGO techniques and their applications in Chemical Engineering, which motivated the preparation of this book. The broad objective of this book is to provide an overview of a number of SGO techniques and their applications to Chemical Engineering. Accordingly, there are two parts in the book. The first part, Chapters 2 to 11, includes description of the SGO techniques and reviews of their recent modifications and Chemical Engineering applications. The second part, Chapters 12 to 19, focuses on Chemical Engineering applications of SGO techniques.

Each chapter in the book is contributed by well-known and active researcher(s) in the area. A brief resume and photo of each of the contributors to the book, are given on the enclosed CD-ROM. Each chapter in the book was reviewed anonymously by at least two experts and/or other contributors. Of the submissions received, only those considered to be useful for education and/or research were revised by the respective contributor(s), and the revised submission was finally reviewed for presentation style by the editor or one of the other contributors. I am grateful to my long-time mentor, Dr. R. Luus, who coordinated the anonymous review of chapters co-authored by me.

The book will be useful to researchers in academia and research institutions, to engineers and managers in process industries, and to graduates and senior-level undergraduates. Researchers and engineers can use it for applying SGO techniques to their processes whereas students can utilize it as a supplementary text in optimization courses. Each of the chapters in the book can be read and understood with little reference to other chapters. However, readers are encouraged to go through the Introduction chapter first. Many chapters contain several exercises at the end, which can be used for assignments and projects. Some of these and the applications discussed within the chapters can be used as projects in optimization courses at both undergraduate and postgraduate levels. The book comes with a CD-ROM containing many programs and files, which will be helpful to readers in solving the exercises and/or doing the projects.

I am thankful to all the contributors and anonymous reviewers for their collaboration and cooperation in producing this book. Thanks are also due to Mr. K.W. Tjan and Ms. H.L. Gow from the World Scientific, for 
their suggestions and cooperation in preparing this book. It is my pleasure to acknowledge the contributions of my postgraduate students (Shivom Sharma, Zhang Haibo, Mekapati Srinivas, Teh Yong Sing, Lee Yeow Peng, Toh Wei Khiang and Pradeep Kumar Viswanathan) to our studies on SGO techniques and to this book in some way or other. I thank the Department of Chemical \& Biomolecular Engineering and the National University of Singapore for encouraging and supporting my research over the years by providing ample resources including research scholarships.

Finally, and very importantly, I am grateful to my wife (Krishna Kumari) and family members (Santosh, Jyotsna and Madhavi) for their loving support, encouragement and understanding not only in preparing this book but in everything I pursue.

Gade Pandu Rangaiah 
This page intentionally left blank 


\section{CONTENTS}

Preface $\quad$ V

Chapter 1 Introduction 1

Gade Pandu Rangaiah

Chapter 2 Formulation and Illustration of Luus-Jaakola

Optimization Procedure

Rein Luus

Chapter 3 Adaptive Random Search and Simulated Annealing Optimizers: Algorithms and Application Issues Jacek M. Jeżowski, Grzegorz Poplewski and Roman Bochenek

Chapter 4 Genetic Algorithms in Process Engineering: Developments and Implementation Issues Abdunnaser Younes, Ali Elkamel and Shawki Areibi

Chapter 5 Tabu Search for Global Optimization of Problems

Having Continuous Variables

Sim Mong Kai, Gade Pandu Rangaiah and

Mekapati Srinivas

Chapter 6 Differential Evolution: Method, Developments and

Chemical Engineering Applications

Chen Shaoqiang, Gade Pandu Rangaiah and

Mekapati Srinivas 
X Contents

Chapter 7 Ant Colony Optimization: Details of Algorithms

Suitable for Process Engineering

V. K. Jayaraman, P. S. Shelokar, P. Shingade,

V. Pote, R. Baskar and B. D. Kulkarni

Chapter 8 Particle Swarm Optimization for Solving NLP and

MINLP in Chemical Engineering

Bassem Jarboui, Houda Derbel, Mansour Eddaly

and Patrick Siarry

Chapter 9 An Introduction to the Harmony Search Algorithm

Gordon Ingram and Tonghua Zhang

Chapter 10 Meta-Heuristics: Evaluation and Reporting

Techniques

Abdunnaser Younes, Ali Elkamel and Shawki Areibi

Chapter 11 A Hybrid Approach for Constraint Handling in

MINLP Optimization using Stochastic Algorithms

G. A. Durand, A. M. Blanco, M. C. Sanchez and

J. A. Bandoni

Chapter 12 Application of Luus-Jaakola Optimization

Procedure to Model Reduction, Parameter

Estimation and Optimal Control

Rein Luus

Chapter 13 Phase Stability and Equilibrium Calculations in

Reactive Systems using Differential Evolution and Tabu Search

Adrián Bonilla-Petriciolet, Gade Pandu Rangaiah, Juan Gabriel Segovia-Hernández and José Enrique Jaime-Leal

Chapter 14 Differential Evolution with Tabu List for Global

Optimization: Evaluation of Two Versions on

Benchmark and Phase Stability Problems

Mekapati Srinivas and Gade Pandu Rangaiah 
Chapter 15 Application of Adaptive Random Search

Optimization for Solving Industrial Water

Allocation Problem

Grzegorz Poplewski and Jacek M. Jeżowski

Chapter 16 Genetic Algorithms Formulation for Retrofitting Heat Exchanger Network

Roman Bochenek and Jacek M. Jeżowski

Chapter 17 Ant Colony Optimization for Classification and

Feature Selection

V. K. Jayaraman, P. S. Shelokar, P. Shingade,

B. D. Kulkarni, B. Damale and A. Anekar

Chapter 18 Constraint Programming and Genetic Algorithm

Prakash R. Kotecha, Mani Bhushan and

Ravindra D. Gudi

Chapter 19 Schemes and Implementations of Parallel

Stochastic Optimization Algorithms:

Application of Tabu Search to Chemical

Engineering Problems

B. Lin and D. C. Miller

Index 